\title{
Identification and Quantification of Andrographolide from Andrographis paniculata (Burm. f.) Wall. ex Nees by RP-HPLC Method and Standardization of its Market Preparations
}

\author{
B. K. Sajeeb ${ }^{1}$, Uttom Kumar ${ }^{1}$, Shimul Halder ${ }^{1}$ and Sitesh C. Bachar ${ }^{2}$ \\ ${ }^{1}$ Department of Pharmaceutical Technology, Faculty of Pharmacy, University of Dhaka. \\ Dhaka-1000, Bangladesh \\ ${ }^{2}$ Department of Pharmacy, Faculty of Pharmacy, University of Dhaka \\ Dhaka-1000, Bangladesh
}

Received: October 14, 2014; Accepted: May 12, 2015; Published (web): June 15, 2015

\begin{abstract}
Andrographis paniculata (Burm. f.) Wall. ex Nees, commonly known as Kalmegh, is widely used as antimalarial drug in herbal and traditional systems. Andrographolide is the major triterpenoid present in the plant and responsible for its therapeutic activities. The identification and quantification of andrographolide were ascertained by various spectrophotometric and chromatographic analyses. The plant sample was extracted with methanol. The amorphous residue obtained from extraction was analyzed for identification of andrographolide by chemical method, TLC, UV-Vis, FT-IR and LCMS/MS analyses. The quantitative estimation of andrographolide content in plant sample was carried out by simple reversed phase HPLC method with $\mathrm{C}_{18}$ column using a mixture of water and methanol (35:65) as mobile phase at a flow rate of $0.7 \mathrm{~mL} / \mathrm{min}$, and the estimated concentration level of andrographolide was found as $38.36 \pm 0.42 \mu \mathrm{g} / \mathrm{mL}$ in the solution of amorphous residue $(50 \mu \mathrm{g} / \mathrm{mL})$. After quantitative determination of andrographolide, standardization of its market preparations was accomplished using the same RP-HPLC method. The estimated \% potencies of andrographolide compared to reference standard in six market preparations were found to be $97.56,98.37,98.21,95.60,98.91$ and 96.40 .
\end{abstract}

Key words: Andrographis paniculata (Burm. f.) Wall. ex Nees, Kalmegh, Andrographolide, RP-HPLC, sepctrophotometry

\section{INTRODUCTION}

Plants have been the basis for medical treatments through much of human history and such traditional medicines are still widely practiced today. The World Health Organization (WHO) estimates that three fourth of the world population presently use herbal medicines for some aspect of primary health care. ${ }^{1}$ Approximately 120 active compounds currently isolated from the higher plants are widely used in modern medicine today. ${ }^{2}$ Beyond the pharmaceutical approaches of plants, there is a wide tendency to utilize herbal products as dietary supplements with the intention of improving the quality of life and

Correspondence to: Sitesh C. Bachar

E-mail: scbachar63@gmail.com

Dhaka Univ. J. Pharm. Sci. 14(1): 71-78, 2015 (June) preventing diseases of elderly people. ${ }^{3}$ Andrographis paniculata (Burm. f.) Wall. ex Nees (family: Acanthaceae) is a herbaceous plant and most commonly used as medicinal plant in the traditional system. ${ }^{4}$ It grows in many South Asian countries and also used as a traditional medicine in China, Hong Kong, Philippines, Malaysia, Indonesia and Thailand. ${ }^{4}$ A. paniculata is the main source of the bitter principle 'andrographolide'. Because of extremely bitter and characteristic taste of $A$. paniculata, it is known as "king of bitters". Beside andrographolide, this plant contains 14-deoxy-11, 12didehydroandrographolide-2, 14-deoxyandrographolide-3, 3, 14-deoxyandrographolide-4, 14-deoxy11-oxoandrographolide-5, neoandrographolide-7, 14deoxyandrographiside- $9^{5}$ in significant quantities. 
The aqueous extract of $A$. paniculata shows antimicrobial activity due to combined effect of arabinogalactan proteins and andrographolide. ${ }^{6}$ It has also been used traditionally for sluggish liver as antidote in case of colic dysentery and dyspepsia. ${ }^{7}$ The fresh leaf juice is a domestic remedy in the treatment of colic pain, loss of appetite, irregular stools and diarrhea. ${ }^{8}$ The active principle, andrographolide is also attributed with some other activities like liver protection ${ }^{9}$, anticancer ${ }^{10}$ and antimalarial activities. ${ }^{11}$ Beside these, A. paniculata shows a broad range of pharmacological effects such as inhibition of replication of the HIV virus, antibacterial activity, antihyperglycemic effects, suppression of various cancer cells, antiinflammatory properties ${ }^{12}$ and many more diseases.

Now-a-days, different analytical methods have been developed for isolation, identification and quantification of andrographolide from indigenous plant sources, and for standardization of its marketed products. These analytical methods are highly selective for evaluating the therapeutic potential of the purified bioactive principles in order to achieve the optimal outcomes. The objectives of the present study were to identify and quantify andrographolide in A. paniculata and standardize its market preparations so that the herbal and traditional manufacturers can produce their products by maintaining quality requirements. In the present study, a simple, precise and reproducible RP-HPLC method has been developed, through which andrographolide in A. paniculata was determined and quantified.

\section{MATERIALS AND METHODS}

Plant materials. The green leaves and stems of A. paniculata were collected from the Medicinal Plant Garden, Faculty of Pharmacy, University of Dhaka, Dhaka-1000, Bangladesh and Square Herbal \& Neutraceuticals Limited, Pabna, Bangladesh in the month of September, 2012. The taxonomical identification of the plant was confirmed by National Herbarium, Bangladesh (accession number: DACB37879). The whole plant material was dried under shade, powdered using blender and stored in air tight container.

Chemicals and instruments. The solvents and reagents for analyses were of analytical grade and used without further purification. Sixty andrographolide capsules, each containing $200 \mathrm{mg}$ of andrographolide, were purchased from six different local herbal and traditional manufacturers. Reference standard of andrographolide with potency $99.06 \%$ (Article No. 89821, Batch No. 1000003992, Germany) was supplied by Square Herbal and Neutraceuticals Ltd, Pabna, Bangladesh. HPLC grade methanol (Sigma Aldrich, Germany) and water purified by Millipore purified system were used for analysis. TLC plate (Aluminium foil precoated with Silica $\left.60 \mathrm{~F}_{254}\right), \quad \mathrm{UV}$-Vis Spectrophotometer (Shimadzu, Japan), FT-IR (Shimadzu, Japan) and LCMS/MS (Shimadzu, Japan) were used. HPLC (Shimadzu, Japan) equipped with a manual injector, a vacuum degasser, a multiple-wavelengths UV/Visible detector (Shimadzu SPD 20A, Japan) and an ODS column namely Capcell Pak ( $150 \mathrm{~mm} \times 4.6 \mathrm{~mm}$ I.D., 5 $\mu \mathrm{m}$ particle size) were used for chromatographic analyses.

Extraction of plant material. About $250 \mathrm{~g}$ of $A$. paniculata plant powder was weighed and moisture content of the sample was determined by KarlFischer method. The plant powder (moisture content $0.132 \%$ ) was placed in a round bottom flask and methanol $(450 \mathrm{~mL})$ was poured in it with uniform mixing. The mixture was then gently warmed in water bath for $60 \mathrm{~min}$ and decanted. The process was repeated for three times. The crude extracts were combined, allowed to cool and filtered to remove the coarse particles and the solvent was evaporated under vacuum to get oily residue. The residue was then extracted with chloroform and the organic layer was collected. An amorphous residue (about $10.6 \mathrm{~g}$ ) was obtained after drying the organic layer which was then stored in air tight container and subjected to further analyses for identification and quantification of andrographolide. 


\section{Identification of andrographolide in plant sample}

Chemical identification. About $0.5 \mathrm{mg}$ of amorphous residue was dissolved in $5 \mathrm{~mL}$ of methanol, then treated with $1 \mathrm{~mL}$ of 2,4dinitrophenylhydrazine and $100 \mathrm{~mL}$ of $2 \mathrm{M} \mathrm{HCl}$ was added. A yellow orange color indicating the presence of andrographolide. ${ }^{13,14}$

About 8 drops of alcoholic potassium hydroxide (10\%) was added to $0.5 \mathrm{mg}$ of amorphous residue and a red color was appeared which kept for $14 \mathrm{~min}$. The red color changed to yellow indicating the presence of andrographolide. ${ }^{15}$

TLC analyses. The amorphous residue was subjected to TLC analyses along with reference standard of andrographolide where a mixture of chloroform, methanol and ethyl acetate at ratio of 7:2:1 was used as the mobile phase. The analyzed TLC plates were then sprayed with 3, 5dinitrobenzoic acid in ethanol $(2 \% \mathrm{w} / \mathrm{v} \text { solution })^{16}$ and $\mathrm{KOH}$ in ethanol $(6 \% \mathrm{w} / \mathrm{v} \text { solution })^{16}$ for visualizing spot position.

Spectral analyses. The residue and standard andrographolide were both scanned for absorption maxima $\left(\lambda_{\max }\right)$ using UV-Vis Spectrophotometer (methanol as blank) within the range of 200 to 400 $\mathrm{nm}$. The characteristic absorption bands for the functional groups of andrographolide were ascertained through FT-IR analyses ( $\mathrm{KBr}$ disc) within the range of 400 to $4000 \mathrm{~cm}^{-1}$ and the molecular weight was determined by LCMS/MS.

\section{Quantitative analyses of andrographolide}

Preparation of sample solutions. The sample solution of $50 \mu \mathrm{g} / \mathrm{mL}$ concentration was made by dissolving the required quantity of amorphous residue in HPLC grade methanol. The solution was thoroughly shaken and sonicated until complete dissolution of the coarse and visible particles. Then the solution was allowed to cool at room temperature and the volume was adjusted to the mark with methanol, and was filtered through $0.45 \mu \mathrm{m}$ filter paper. A total of seven sample solutions of $50 \mu \mathrm{g} / \mathrm{mL}$ concentration were prepared and stored in clean vials bellow $10{ }^{\circ} \mathrm{C}$.
Preparation of standard solutions. The standard stock solution of $160 \mu \mathrm{g} / \mathrm{mL}$ concentration was prepared with reference andrographolide in HPLC grade methanol with shaking and sonication. The standard solutions with the concentrations of $140,120,100,60,40$ and $20 \mu \mathrm{g} / \mathrm{mL}$ were then prepared by suitable dilution of stock solution with methanol. Finally the prepared standard solutions were filtered separately through $0.45 \mu \mathrm{m}$ filter paper and stored bellow $10{ }^{\circ} \mathrm{C}$.

Chromatographic condition. The andrographolide content in amorphous residue was determined by reversed phase HPLC with $\mathrm{C}_{18}$ column. The elution was carried out with a binary solvent system of water and methanol $(35: 65)$ as mobile phase at a flow rate of $0.7 \mathrm{~mL} / \mathrm{min}$ maintaining ambient temperature. The sample injection volume was $20 \mu \mathrm{L}$, and the analyses were monitored with the UV-Vis detector at $223 \mathrm{~nm}$.

Quantification of andrographolide in plant sample. The standard solutions of different concentrations were analyzed with the RP-HPLC method and peak areas were recorded. A calibration curve was prepared by using peak areas and concentrations of standard solutions. Sample solutions $(50 \mu \mathrm{g} / \mathrm{mL})$ were analyzed and the peak areas were recorded and concentration of andrographolide in sample solutions were determined by using calibration curve.

\section{Standardization of market preparations}

Preparation of market samples. Ten capsules were taken for each market preparation (200 mg andrographolide capsule) and average weight of the contents was determined. The powdered sample equivalent to $200 \mathrm{mg}$ of andrographolide was taken in a clean and dry $100 \mathrm{ml}$ volumetric flask. Methanol $(10 \mathrm{~mL})$ was added, and shaken thoroughly and then sonicated for $5 \mathrm{~min}$ for complete dissolution of drug. The solution was allowed to cool at room temperature and the volume was made up to the mark with methanol. The solution was filtered through Whatman filter paper (No. 42) and then finally filtered through $0.45 \mu \mathrm{m}$ disk filter. It was kept in air 
tight containers and stored below $10{ }^{\circ} \mathrm{C}$. After suitable dilution, the solutions of $50 \mu \mathrm{g} / \mathrm{mL}$ concentration were prepared with HPLC grade methanol.

Estimation of andrographolide in market preparations. The solutions of market samples were analyzed through RP-HPLC method maintaining similar chromatographic conditions mentioned. The sample solutions $(50 \mu \mathrm{g} / \mathrm{mL})$ were injected and the peak areas were recorded at defined retention time. Andrographolide concentration in market samples were determined using the calibration curve for reference standard. All determinations were conducted in triplicate.

\section{RESULTS AND DISCUSSION}

TLC analyses. The $R_{f}$ value of residue (0.38) and standard andrographolide (0.37) matched completely, which indicated the presence of andrographolide in amorphous residue (Figure 1).

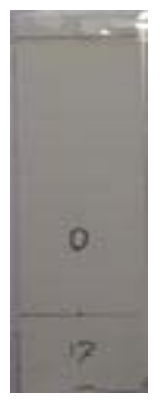

Figure 1. TLC analysis of A. paniculata amorphous residue.
Spectral analyses. The TLC analyses showed the presence of andrographolide in amorphous residue of A. paniculata which was further confirmed through UV-Vis, FT-IR and LCMS/MS analyses. The residue and standard andrographolide were subjected to UV-Vis spectrophotometry and $\lambda_{\max }$ was observed at $223 \mathrm{~nm}$ for both. The FT-IR spectrum of the extracted plant residue showed (Figure 2) the characteristic absorption bands at $1454 \mathrm{~cm}^{-1}$ (stretching vibration of $\mathrm{C}=\mathrm{C}$ bond); $1648,1675 \mathrm{~cm}^{-1}$ (stretching vibration of $\mathrm{C}=\mathrm{O}$ ); 2927, 2958, $2980 \mathrm{~cm}^{-1}$ (stretching vibration of $\mathrm{C}-\mathrm{H}$ ) and $3322,3397 \mathrm{~cm}^{-1}$ (stretching vibration of $\mathrm{O}-\mathrm{H}$ ). Similar characteristics were observed in case of standard andrographolide. ${ }^{17}$

The molecular weight of compound in amorphous residue was determined through LCMS/MS method and the observed value was at $m / z$ $349.1[\mathrm{M}-\mathrm{H}]^{+}$(Figure 3), which was found to be similar with the reported literature. ${ }^{18}$

Quantification of andrographolide in plant sample. Quantification of andrographolide in amorphous residue was carried out through RPHPLC method. A standard solution of reference andrographolide was injected and the retention time was found to be $7.557 \mathrm{~min}$ (Figure 4).

A calibration curve was prepared by using peak areas and concentration (Table 1) of standard solutions, and the content of andrographolide in residue was quantified by using linear regression equation of the calibration curve.

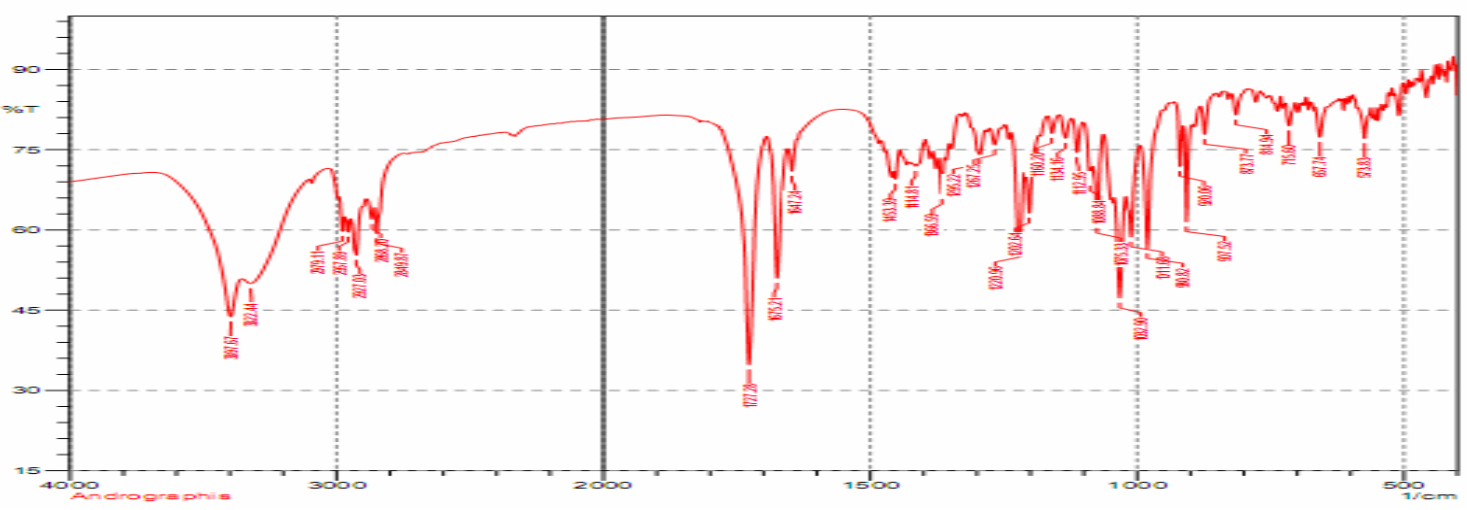

Figure 2. FT-IR spectrum of A. paniculata amorphous residue. 


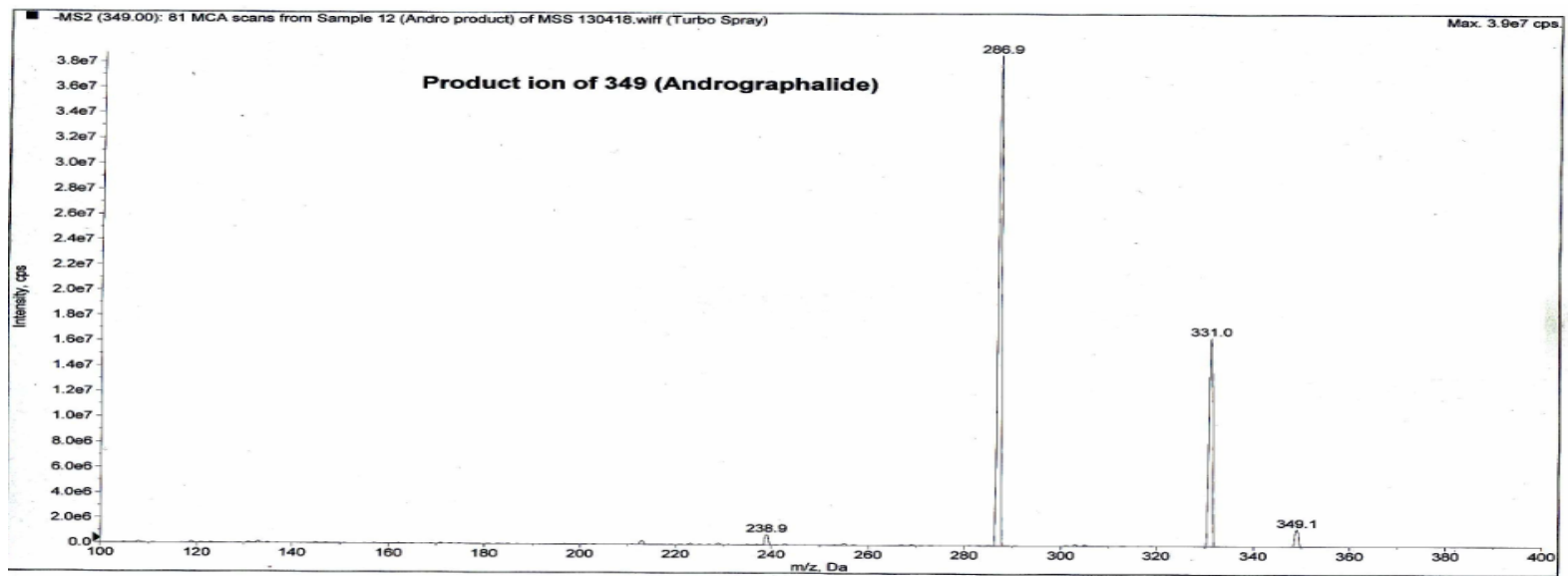

Figure 3. LCMS/MS spectrum of A. paniculata amorphous residue.

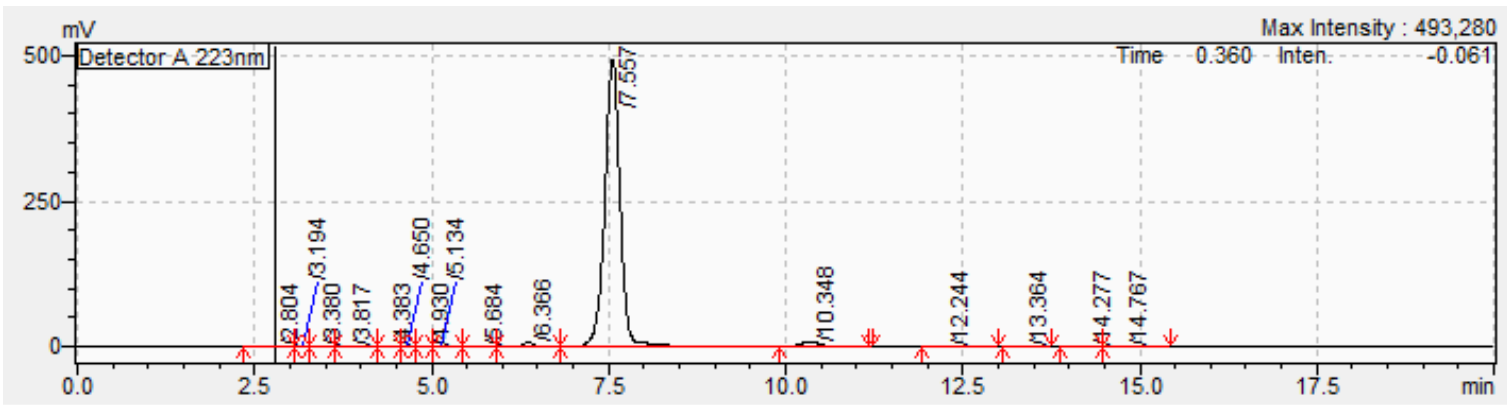

Figure 4. Chromatogram for reference standard of andrographolide observed by RP-HPLC.

Table 1. Peak areas of RP-HPLC chromatogram for various concentrations of reference standard of andrographolide.

\begin{tabular}{ccc}
\hline No. & $\begin{array}{c}\text { Concentration } \\
(\mu \mathrm{g} / \mathrm{mL})\end{array}$ & Peak area \\
\hline 1 & 20 & 1317009 \\
2 & 40 & 2792160 \\
3 & 60 & 3986327 \\
4 & 100 & 5959159 \\
5 & 120 & 7443306 \\
6 & 140 & 8245356 \\
\hline
\end{tabular}

The linear regression equation of calibration curve was: $\mathrm{Y}=57250 \mathrm{X}-37719$

Where, $\mathrm{X}=$ concentration and $\mathrm{Y}=$ peak area with correlation coefficient $\left(\mathrm{R}^{2}\right), 0.995$ (Figure 5).

The solution of amorphous residue $(50 \mu \mathrm{g} / \mathrm{mL})$ was injected maintaining the similar chromatographic condition of reference standard and the retention time for andrographolide was observed at $7.570 \mathrm{~min}$ (Figure 6). The analyses of residue were replicated for seven times with the prepared sample solutions and the peak areas were obtained. The estimated quantity of andrographolide was $38.36 \pm 0.42 \mu \mathrm{g} / \mathrm{mL}$ in the solution of amorphous residue (Table 2).

\section{Standardization of market preparations}

Solutions of six market preparations $(50 \mu \mathrm{g} / \mathrm{mL})$ were analyzed and each chromatogram showed different peak areas at defined retention time (Figure 7).

The concentration of andrographolide in each market preparation was determined by using the linear regression equation of calibration curve for reference standard. The amount of andrographolide in capsules were found to be $195.121 \pm 1.545 \mathrm{mg}$, $196.743 \pm 1.926 \mathrm{mg}, 196.420 \pm 0.856 \mathrm{mg}, 191.199 \pm$ $0.735 \mathrm{mg}, 197.825 \pm 1.169 \mathrm{mg}$ and $192.803 \pm 0.184$ mg with the estimated \% potency of $97.56,98.37$, 98.21, 95.60, 98.91 and 96.40, respectively (Table 3). 


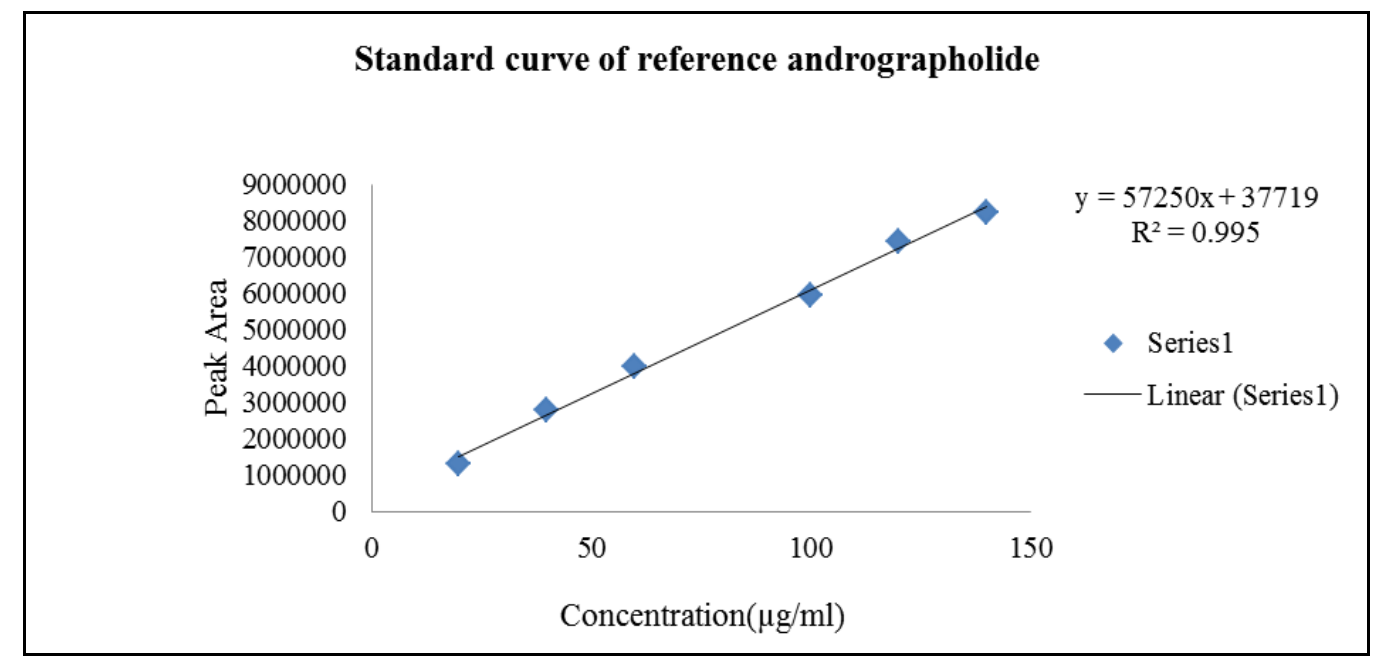

Figure 5. Calibration curve for reference standard of andrographolide.

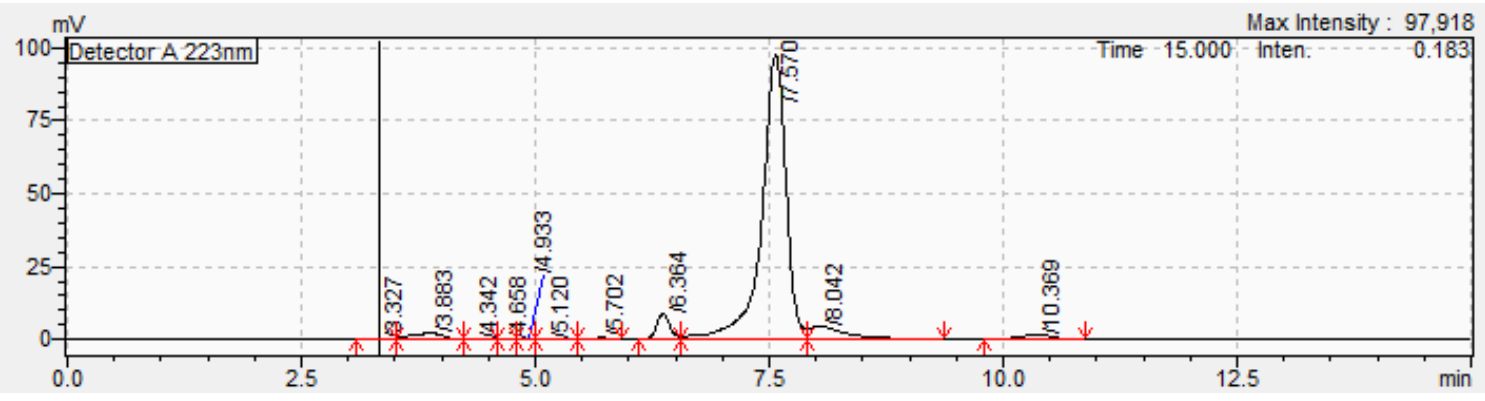

Figure 6. RP-HPLC profiles of A. paniculata amorphous residue.

Table 2. Quantification of andrographolide in amorphous residue.

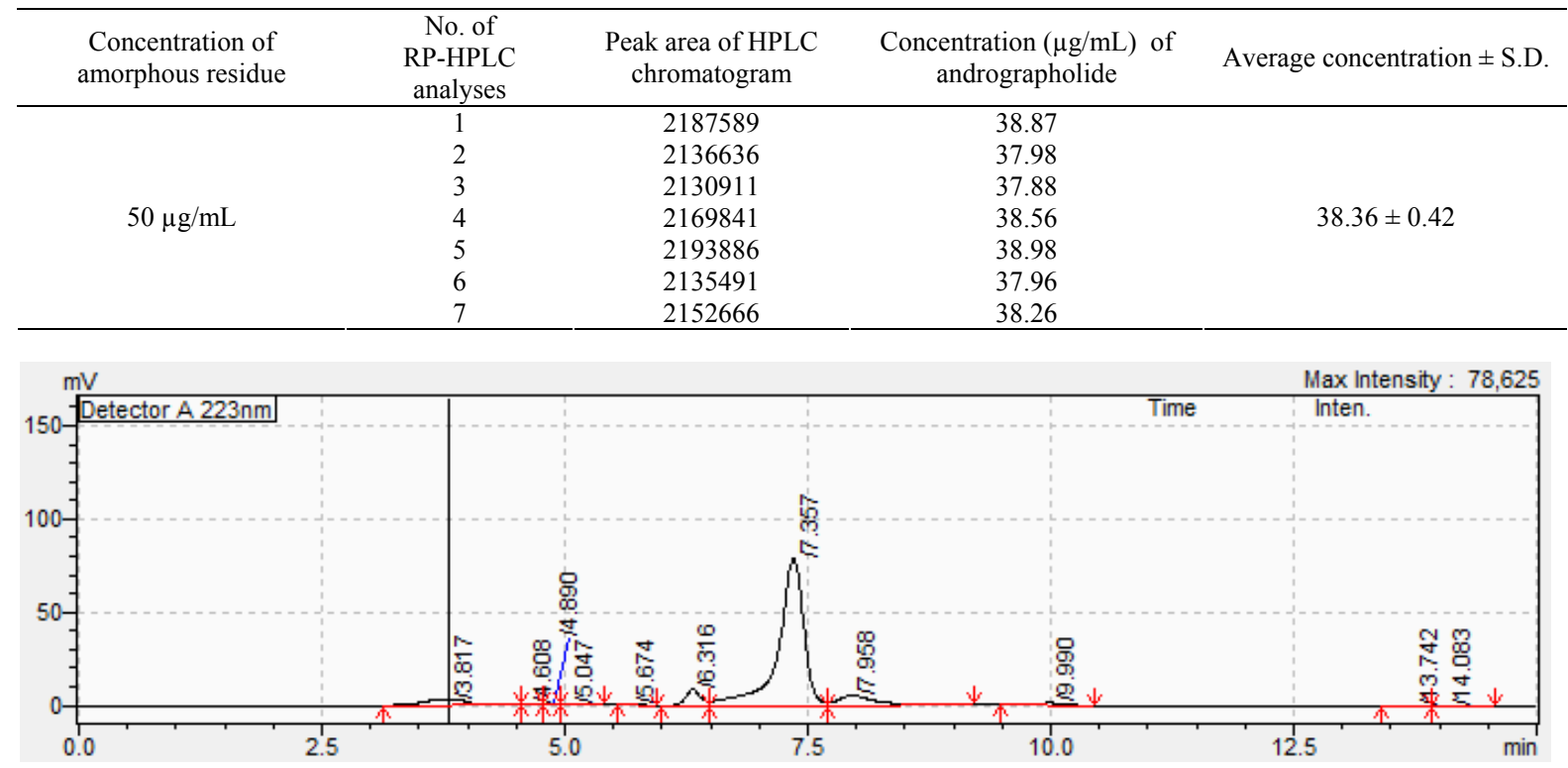

Figure 7. Chromatogram of A. paniculata market preparations obtained during RP-HPLC. 
Table 3. Estimation of andrographolide in market preparations $(50 \mu \mathrm{g} / \mathrm{mL})$.

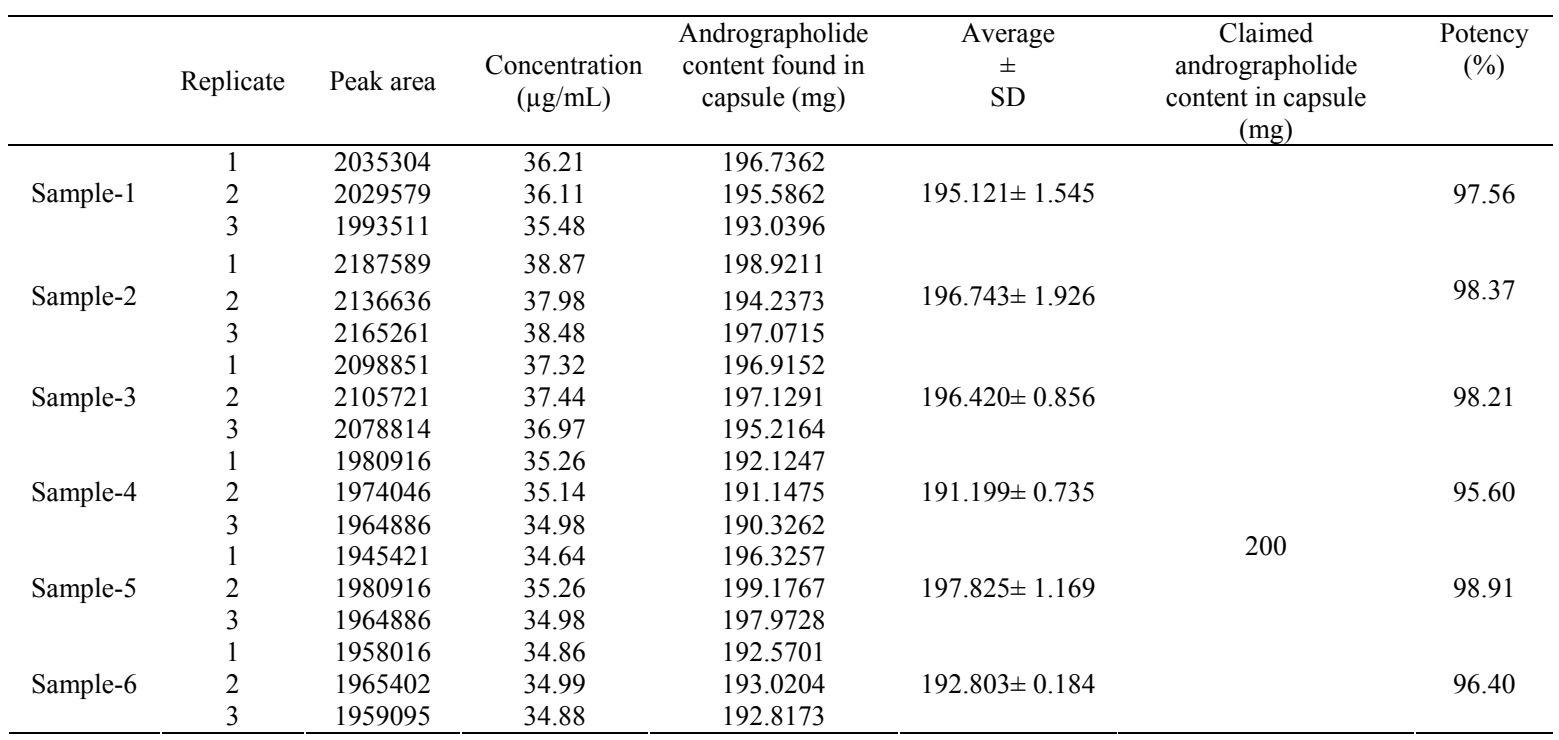

Standardization of $A$. paniculata preparations were accomplished through identification, quantification and comparative analyses between standard andrographolide and its market preparations. The results showed that market preparations contained significant quantity of andrographolide compared to reference standard. The described methods have the advantages of simple, precise, less time consuming and more convenient especially for routine analyses, and may be used for evaluating the quality of herbal and traditional medicines by their manufacturers.

\section{CONCLUSION}

The developed RP-HPLC method along with TLC, UV-Vis, FT-IR and LCMS/MS are highly efficient for identification and quantification of andrographolide in A. paniculata. Now-a-days, most of the herbal and traditional manufacturers are marketing andrographolide preparations for its potential therapeutic activities but due to lack of proper instrumentations and knowledge, manufacturers cannot maintain the desired quality requirements of the preparations. For this reasons, we have developed the prescribed method which is simple, sensitive, statistically validated and ensures the quality requirement of the products. All these methods will open up a new door for the herbal and traditional manufacturers to identify, quantify the phytomarker and standardize their market preparations by meeting the regulatory requirements imposed by regulatory authorities.

\section{ACKNOWLEDGEMENTS}

The authors are indebted to the authority of Square Herbal and Neutraceuticals Limited (Pabna, Bangladesh) for supplying reference standard of andrographolide. The authors would also like to express gratitude to Prof. Dr. Aftab Uddin, Department of Genetic Engineering and Biotechnology, University of Dhaka, Dhaka-1000, Bangladesh for his support during the study.

\section{REFERENCES}

1. World Health Organization, 2000. Promoting the role of traditional medicine in health systems: a strategy for the African Region 2001-2010 (document reference AFR/ RC50/ Doc.9/R), Harare.

2. Fabricant, D.S. and Farnsworth, N.R. 2001. The value of plants used in traditional medicine for drug discovery. Environ. Health Perspect. 109, 69-75.

3. Massimo, M. 2003. Dietary supplements of plant originnutrition and health approach, Taylor \& Francis Ltd., New York, Chapter 3, pp. 26-29. 
4. Tang, W. and Eisenbrand, G. 1992. Chinese drugs of plant origin: Chemistry, pharmacology, and use in traditional and modern medicine. Pharmazie unserer Zeit. 21, 281-282.

5. Poonam K., Tiwari, U.K., Shukla, A. and Gaur, A.K. 2010. Chemical constituents isolated from Andrographis paniculata Nees. Indian J. Chem. 49B, 356-359.

6. Singha, P.K., Roy, S. and Dey, S. 2003. Antimicrobial activity of Andrographis paniculata Nees. Fitoterapia 74, 692-694.

7. Handa, S.S. and Sharma, A. 1990. Hepatoprotective activity of andrographolide from Andrographis paniculata Nees against carbon tetrachloride. Indian J. Med. Res. 92, 276-283.

8. Saxena, S., Jain, D.C., Bhakuni, R.S. and Sharma, R.P. 1998. Chemistry and pharmacology of Andrographis species. Indian Drugs 35, 458-467.

9. Saraswat, B., Visen, P.K.S., Patnaik, G.K. and Dhawan, B.N. 1995. Effect of andrographolide against galactosamine induced hepatotoxicity. Fitoterapia 66, 415-420.

10. Lal, J., Tripathi, H.C. and Tandon, S.K. 1986. Antidiabetic activity of andrographolide. Indian J. Pharmacol. 18, 58-61.

11. Rahman, N.N., Furuta, T., Kojima, S., Takane, K. and Mohd, M.A. 1999. Antimalarial activity of extracts of Malaysian medicinal plants. Ethnopharmacol. J. 64, 249-254.

12. Yang, S., Evens, A.M., Prachand, S., Singh, A.T., Bhalla, S. and David, K. 2010. Mitochondrial mediated apoptosis in lymphoma cells by the diterpenoid lactone andrographolide: the active component of Andrographis paniculata Nees. Clin. Cancer Res. 16, 4755-4768.
13. Ali, M. 2009. Pharmacognosy and Phytochemistry. CBS publishers \& distributors, Delhi, Chapter 3, pp. 181-182.

14. Mukherjee, P.K. 2002. Quality Control of herbal drugs: An approach to evaluation of botanicals. Business Horizons Pharmaceutical Publisher, New Delhi, pp. 578-580.

15. Medicinal Plant Research Institute, Department of Medical Science, Ministry of Public Health, 1999. Standards of Thai Herbal Medicine: Andrographis paniculata Nees. The War Veterans Organization Press, Bangkok, pp. 66-67.

16. Meenu, S. and Sharma, R.G. 2013. Identification, purification and quantification of andrographolide from Andrographis paniculata (Burm. f.) Nees by HPTLC at different stages of life cycle of crop. J. Curr. Chem. Pharm. Sci. 3, 23-32.

17. Cuthbertson, D.J., Johnson, S.R., Piljac-Žegarac, J., Kappel, J., Schäfer, S., Wüst, M., Ketchum, R.E.B., Croteau, R.B., Marques, J.V., Davin, L.B., Lewis, N.G., Rolf, M., Kutchan, T.M., Soejarto, D.D. and Lange, B.M. 2013. Accurate masstime tag library for LC/MS based metabolite profiling of medicinal plants. Phytochemistry 91, 187-197.

18. Dilip, B.J. and Bhaskar, N.T. 2012. Quantitative estimation of andrographolide by reverse phase high liquid chromatography method from Andrographis paniculata. Int. J. Phytopharm. 2, 149-153. 